\title{
The Intervention of Learning Mathematics by Using Identifying Errors Technique on Demographic Behaviours and Cognitive Abilities
}

\author{
Siti Ramizah binti Jama*, Wan Hartini Wan Hassan, Siti Nursyahira Zainudin, Bushra Abdul Halim, \\ Siti Fairus Fuzi, Nurul Emyza Zahidi
}

Faculty of Computer and Mathematical Sciences, Universiti Teknologi MARA Cawangan Melaka, Alor Gajah Campus, Malaysia

Received August 1, 2019; Revised October 10, 2019; Accepted February 20, 2020

Copyright $\subseteq 2020$ by authors, all rights reserved. Authors agree that this article remains permanently open access under the terms of the Creative Commons Attribution License 4.0 International License

\begin{abstract}
The probability of students to make a mathematical error in problem solving is high. Problem solving skills in mathematics are important. The purpose of this study is to explore to what extent the intervention of learning methods by using identifying errors technique to reduce mathematical errors in learning mathematics. Previous studies show that lack of comprehension of mathematical concepts among students leads to numerous mathematical errors. For this study, the participants are 134 Mengubah Destini Anak Bangsa (MDAB) students from Pre-Commerce programme in Universiti Teknologi MARA Cawangan Melaka (UiTMCM), for semester September 2017 - January 2018. The data collected for this study is from the pre-quiz, post-quiz and identifying errors exercises (IEE) scores. Pre-quiz was issued to students during the first meeting of Intensive Mathematics I (MAT037) class. Thereafter, sessions of mathematics class with emphasis on mathematical errors took place. The postquiz was given to participants on the last day of the fourteenth week. To emphasize the study two groups were made. IEE_1 is a group of students who did all IEE while IEE_2 is a group who did only parts of IEE. The findings show no significant difference between gender, resided location and socio-economic status of the students. However, it was shown that Modern Mathematics SPM results have a significant impact on the scores of IEE. In addition, results also show no significant difference in the mean scores between students in IEE_1 and IEE_2 for prequiz. However, after the intervention of identifying errors techniques, it was revealed that the mean scores for postquiz differ significantly higher for IEE_1 group compared to IEE_2 group.
\end{abstract}

Keywords Sijil Pelajaran Malaysia, Mathematical Errors, Intensive Mathematics I (MAT037), Mengubah Destini Anak Bangsa (MDAB), Identifying Errors
Exercises (IEE)

\section{Introduction}

The majority of students seem to have a mindset that mathematics is a tough subject. In learning mathematics, students frequently make mathematical errors especially in solving mathematical problems. The most frequently asked question by mathematics instructor is, "Why do students make errors when solving mathematical problems?". This problem still happening at the university levels. Most of the errors are repeatedly exhibited by students despite reminders from their teachers. Repeating errors are concerned with problem solving difficulties faced by students. According to [4], students will face many obstacles during teaching and learning mathematics as problem solving skills are complex to learn. Besides, previous studies also highlighted those mathematical difficulties are related to cognitive inabilities and poor mathematics skills among students.

In a study conducted by [9], the common errors made by students were number form conversion errors, number operations errors, calculation errors, comprehension errors, factoring errors, concept errors, random errors, expanding errors and transformation errors.

In Universiti Teknologi MARA, mathematics course is a core course for pre-diploma students where passing is compulsory in order to pursue their studies at diploma level. Namely as MAT037, it is a basic mathematics course consisting of six chapters. The chapters include arithmetic and algebra, equations and functions, index and logarithms, sequence, applications of mathematics in business and introduction to basic statistics. 
During the first class session, it is very important for instructors to obtain some information on students' mathematical backgrounds. In the case of pre-diploma students, their Modern Mathematics achievements in SPM are important for instructors to study. While teaching mathematics in class, the most common mathematical errors should be emphasized regardless of the chapters taught. Besides that, students should get feedbacks about the errors they made. By doing so, students could enhance their learning and improve their grades if they understand why, how and where they do wrong.

Different students develop different cognitive abilities through higher order thinking skills. This is, therefore, the reason why during the learning process, students show different levels of understanding [12]. One of the most effective forms of this kind of intervention is one-on-one brain training. Thus, this research attempts to investigate the intervention effects of cognitive abilities of higher order thinking skills through analyzing and identifying error skills.

The objective of this study is to examine any significant difference in identifying error scores (AVE_IE) between gender, resided location, socio-economic status and SPM Modern Mathematics grade points. Besides, this study also aims at evaluating intervention effects of cognitive abilities through identifying error skills on students' pre-quiz and post-quiz scores.

\section{Literature Review}

Similar to this study, [9] categorized eighteen types of mathematical error committed by MDAB students. Their findings also concluded that gender has no moderate effects on the relationship between the performance level of MDAB students and the number of occurrences of mathematical errors made by the students. In contrast, [3] reported that the difference of frequencies in committing errors of mathematical operations in Algebra among gender is significant whereby male students were found to commit more errors compared to female students.

Meanwhile, [1] discovered that male and female students who learnt algebra by using Problem Based Learning did not significantly differ in their mathematics' scores. This finding concludes that male and female students are capable of competing and collaborating during Mathematics lessons.

Past studies have indicated that learning through error technique was found to help students improve their knowledge. [2] applied this technique in learning algebra and the results revealed that students who studied based on either incorrect examples or combination of examples which consists of correct and incorrect examples gained more knowledge and increased in understanding algebraic conceptual than students who studied only by using correct examples.
In relation to cognitive abilities, [6] identified thirteen elements of high order thinking skills, namely, comparing, classifying, inductive reasoning, deductive reasoning, analyzing errors, constructing support, analyzing perspectives, abstracting, decision making, investigation, problem solving, experimental enquiry and invention. In teaching and learning process, thinking skills are the fundamental of learning.

In a study by [12], classifying, analyzing errors, analyzing perspectives, abstracting, decision making and problem solving skills were rated low among technical education students. Their findings also indicated that there was a very low insignificant positive relationship between the level of higher order thinking skills with gender, academic achievement and socio-economic status. They then concluded that gender, academic achievement, and socio-economic status do not affect students' thinking skills. This study focused on one of the elements of high order thinking skills that is, analyzing errors.

The art of mathematics is needed when solving mathematical problems. In his study, [10] pointed out the importance of cognitive skills in solving mathematical problems. He further highlighted that, cognitive skills, such as abilities to give focus, to make meaningful perceptions, to think logically and to use memory effectively are important in learning mathematics and solving mathematical problems.

Geary [5] concluded that interference abilities in cognitive skills would be the reason why students face difficulties in mathematics. This idea is also supported by [11] who noted that many students are incompetent in acquiring many mathematics skills. This may be due to the lack of cognitive abilities in learning, such as the ability to recall, memorize and perceive and influence the efficiency of problem-solving. Consequently, this factor has caused students to face difficulties in mathematic problem solving skills. [11] further added that although students acquired other mathematics skills, but without the transfer of information skill, they might not be able to understand and make effective connection of the information in the problems.

According to [8], there are nine reasons for students committing errors in solving mathematics questions. The nine reasons are incomplete mastery of number facts, poor computation skills, unable to connect conceptual aspects of mathematics, inefficiency in transferring knowledge, difficulty to make meaningful connection among information, incompetency to transform information mathematically, incomplete mastery of mathematical terms, incomplete understanding of mathematical language and difficulty in understanding a mathematical concept.

[7] conducted a study in comparing SPM Mathematics results with a course on Mechanical Engineering programs namely Thermodynamics 1 (JJ207) and Engineering Mechanics (JJ205). Their analysis found that there was a very strong significant relationship between SPM results 
and the students' performance in the subject taken during diploma. Their findings illustrated that if students were able to achieve good results in Mathematics in SPM, it will help them in mastering engineering courses in polytechnics.

Based on previous studies, it can be concluded that students who obtain good results in SPM Mathematics are able to sustain their performance in any courses involving calculations at diploma level.

\section{Research Methodology}

\subsection{Sampling}

All 350 MDAB students enrolling in semester September 2017 - January 2018 and sitting for MAT037 January 2018 final examination were taken as the population of the study. These students of different demographic backgrounds were assigned to 13 groups. Using cluster sampling technique, six groups of students were randomly selected and all students from the selected groups were taken as the samples of the study. Data were collected from 134 students from the six selected groups.

\subsection{Data Collection Method}

Data were collected primarily using a questionnaire to gather data on students' demographic background; gender, age, family monthly income, students' resided location and SPM Modern Mathematics results. Primary data were also collected from pre-quiz scores, post-quiz scores and identifying errors exercises (IEE) scores. Pre-quiz and post quiz were conducted to evaluate the effects of identifying errors method used in learning basic mathematics among MDAB students. Pre-quiz was given before the learning session started at the beginning of the semester while the post-quiz was given at the last week of the semester. The total marks for both quizzes are 30 marks. After learning sessions of each sub-chapter of a chapter, students were asked to answer 20-minutes identifying errors exercises and the scores were recorded. Identifying errors exercises consisted of four to five questions with errors noticeable in the solutions. Students were asked to identify and circle the errors in the solutions that first occurred and they were then required to write the correct solutions for the posited questions.

\subsection{Analysis of Data}

Identifying errors exercises (IEE) scores is given as rubric scale of 1 to 5 . The description of each rubric is shown in Table 1.
Table 1. Rubric Scale of Identifying Errors Exercises

\begin{tabular}{|c|c|l|}
\hline \multirow{5}{*}{ Scale } & 1 & Student is unable to identify errors. \\
\cline { 2 - 3 } & 2 & $\begin{array}{l}\text { Student can identify some of the errors but is unable } \\
\text { to provide solutions for the errors identified. }\end{array}$ \\
\cline { 2 - 3 } & 3 & $\begin{array}{l}\text { Student can identify some of the errors and manage } \\
\text { to write the correct solutions for some of the errors. }\end{array}$ \\
\cline { 2 - 3 } & 4 & $\begin{array}{l}\text { Student can identify all the errors and manage to } \\
\text { write the correct solutions for some of the errors. }\end{array}$ \\
\cline { 2 - 3 } & 5 & $\begin{array}{l}\text { Student can identify all the errors and manage to } \\
\text { write the correct solutions for all the errors identified. }\end{array}$ \\
\hline
\end{tabular}

Students were divided into two independent groups based on the identifying errors exercises; 1 - did all identifying errors exercises (IEE_1) and 2 - did some identifying errors exercises (IEE_2).

Research objective 1 attempts to examine any significant difference in AVE_IE between each of the predictors; gender (1 - male, 2 - female), resided location (1- rural, 2 - urban), socio-economic status (1 - less than RM2000, 2 - RM2000 - RM3000, 3 - more than RM3000) and SPM Modern Mathematics results (1 - Excellent, 2 - Distinction, 3 - Pass). The statistical techniques used in this study were independent sample t-test and Analysis of Variance (ANOVA). For research objective 2, the independent variable is the IEE group while the dependent variables are pre-quiz and post-quiz scores. This study intends to evaluate to what extent the intervention of identifying errors technique affects students' pre-quiz and post-quiz scores. Independent sample t-test was used to analyze these data.

\section{Findings}

The demographic backgrounds of students such as gender, age, students' resided location and SPM Modern Mathematics results are shown in Table 2.

Table 2. Respondents' Demographic

\begin{tabular}{|l|c|c|}
\hline \multicolumn{1}{|c|}{ Demographic Variable } & $\begin{array}{c}\text { Number of } \\
\text { Respondents }\end{array}$ & Percent \\
\hline Gender & & \\
Male & 50 & 37.3 \\
Female & 84 & 62.7 \\
\hline Age & & \\
18 years & 126 & 94.0 \\
19 years & 5 & 3.8 \\
20 years & 3 & 2.2 \\
\hline Students' resided location & & \\
Rural & 54 & 40.3 \\
Urban & 80 & 59.7 \\
\hline SPM Modern Mathematics & & \\
results & & 6.7 \\
A & 9 & 9.7 \\
B & 13 & 21.6 \\
C & 29 & 39.6 \\
D & 53 & 22.4 \\
E & 30 & \\
\hline
\end{tabular}


Based on the data collected, $63 \%$ of respondents were females and $37 \%$ were males. Most of the students (94\%) were 18 years old. The majority of them $(59.7 \%)$ resided in urban residential area. During SPM, the majority of the students $(39.6 \%)$ obtained grade D for their Modern Mathematics, $22.4 \%$ obtained grade E and $21.6 \%$ scored grade C. Only $6.7 \%$ scored A and $9.7 \%$ scored B. The statistics revealed that more than $60 \%$ of MDAB students were below average students based on their SPM Modern Mathematics results.

A statistical independent t-test was conducted to analyze any significant differences between each gender, resided location, socio-economic status and SPM Modern Mathematics results and cognitive abilities through identifying errors exercises (IEE). Findings showed that there was no significant difference between gender and identifying errors average scores. This means that MDAB students had the same level of identifying errors skills. This also indicates that the thinking skills between male and female MDAB students were at an equal level. Likewise, there was also no significant difference noted between resided location and socio-economic status and scores of identifying errors exercises.

However, SPM Modern Mathematics results were shown to have a significant effect $(\mathrm{F}(2,131)=11.268$, $\mathrm{p}<$ $0.05)$ on scores of identifying errors exercises. Results also indicated that students with excellent (grade A) results in SPM Modern Mathematics that were able to identify all errors and manage to write the correct solutions for some of the errors, compared to average (grade C) and below average (grade D and E) students. The results are shown in Table 3 .

In addition, an independent-samples t-test was conducted to study the effects of the intervention of identifying errors technique on students' pre-quiz and postquiz scores. Before the intervention, the results showed that there was no significant difference $(\mathrm{t}(133)=0.739, \mathrm{p}>$ $0.05)$ in the pre-quiz scores for IEE_1 group (mean $=6.81$, $\mathrm{SD}=5.133)$ and IEE_2 group $($ mean $=6.14, \mathrm{SD}=4.397)$. However, after the intervention, the results showed statistically significant differences $(\mathrm{t}(133)=2.670, \mathrm{p}<$ $0.05)$ in post-quiz scores for IEE_1 group (mean $=20.79$, $\mathrm{SD}=5.916)$ and IEE_2 group $($ mean $=17.81, \mathrm{SD}=6.483)$.

Table 3. Effects of Cognitive Abilities on Gender, Resided Location, Socio-Economic Status and SPM Modern Mathematics Results

\begin{tabular}{|c|c|c|c|c|c|c|}
\hline \multicolumn{2}{|c|}{$\begin{array}{l}\text { Independent } \\
\text { Variables }\end{array}$} & $\mathrm{N}$ & $\begin{array}{c}\text { Mean Score of } \\
\text { Identifying Errors } \\
\text { (AVE_IE) }\end{array}$ & Std. Deviation & Test Value & P-Value \\
\hline \multirow{2}{*}{ Gender } & Male & 50 & 3.43 & 0.728 & \multirow{2}{*}{$\begin{array}{l}t(132)= \\
-1.965\end{array}$} & \multirow{2}{*}{0.052} \\
\hline & Female & 84 & 3.66 & 0.648 & & \\
\hline \multirow{2}{*}{ Resided location } & Rural & 54 & 3.61 & 0.698 & \multirow{2}{*}{$\mathrm{t}(132)=0.533$} & \multirow{2}{*}{0.595} \\
\hline & Urban & 80 & 3.55 & 0.682 & & \\
\hline \multirow{4}{*}{$\begin{array}{l}\text { Socio-economic } \\
\text { status }\end{array}$} & Less than RM1000 & 32 & 3.65 & 0.623 & \multirow{4}{*}{$F(3,130)=0.443$} & \multirow{4}{*}{0.723} \\
\hline & $\begin{array}{l}\text { RM1000 and less than } \\
\text { RM2000 }\end{array}$ & 52 & 3.58 & 0.825 & & \\
\hline & $\begin{array}{l}\text { RM2000 and less than } \\
\text { RM3000 }\end{array}$ & 33 & 3.58 & 0.493 & & \\
\hline & RM3000 and more & 17 & 3.41 & 0.685 & & \\
\hline \multirow{3}{*}{$\begin{array}{c}\text { SPM Modern } \\
\text { Mathematics results }\end{array}$} & Excellent & 9 & 4.37 & 0.453 & \multirow{3}{*}{$F(2,131)=11.268$} & \multirow{3}{*}{$0.000^{*}$} \\
\hline & Distinction & 41 & 3.75 & 0.640 & & \\
\hline & Pass & 84 & 3.41 & 0.653 & & \\
\hline
\end{tabular}

Table 4. Intervention of Identifying Errors Technique on Pre-Quiz and Post-Quiz

\begin{tabular}{|c|c|c|c|c|c|c|c|c|}
\hline $\begin{array}{l}\text { Dependent } \\
\text { variable }\end{array}$ & Group & $\mathrm{N}$ & Mean Score & $\begin{array}{c}\text { Overall Mean } \\
\text { Score }\end{array}$ & SD & t-value & $\mathrm{df}$ & p-value \\
\hline \multicolumn{9}{|c|}{ BEFORE INTERVENTION } \\
\hline \multirow{2}{*}{ Pre-quiz } & IEE_1 & 89 & 6.84 & \multirow{2}{*}{6.60} & 5.154 & \multirow{2}{*}{0.770} & \multirow{2}{*}{132} & \multirow{2}{*}{0.442} \\
\hline & IEE_2 & 45 & 6.14 & & 4.397 & & & \\
\hline \multicolumn{9}{|c|}{ AFTER INTERVENTION } \\
\hline \multirow{2}{*}{ Post-quiz } & IEE_1 & 89 & 20.77 & \multirow{2}{*}{19.78} & 5.947 & \multirow{2}{*}{2.638} & \multirow{2}{*}{132} & \multirow{2}{*}{$0.009 * *$} \\
\hline & IEE_2 & 45 & 17.81 & & 6.483 & & & \\
\hline
\end{tabular}

** Significant at 0.01 level 


\section{Conclusions}

The demographic factors such as gender, resided location and socio-economic status of students show no significant effects on cognitive abilities through identifying errors exercises. The findings show that there was no significant difference between genders on identifying errors exercises. This means all MDAB students whether males or females have the same level of identifying errors skills. Similarly, there were also no significant differences between resided location and socio-economic status of the students and identifying errors exercises scores. However, SPM Modern Mathematics results were shown to have a significant impact on identifying errors exercises scores. Results indicated that students with excellent results in Modern Mathematics could significantly identify all the errors and manage to write the correct solutions for some of the errors compared to average performing students.

This study highlighted the use of identifying errors technique in learning basic mathematics. The findings proved that students' understanding in basic mathematics course was improved after the intervention of the identifying errors method. To prove the effectiveness of this learning method, two groups of students were formed; IEE_1 group with students who did all identifying errors exercises and IEE_2 group with students who did only some of identifying errors exercises. Before the intervention of identifying errors method, results showed that there was no significant difference in their pre-quiz scores. However, after the intervention, IEE_1 group significantly outperformed the IEE_2 group in the postquiz scores. The results concluded that the identifying errors learning method has a positive effect on students' understanding of learning mathematics. Based on this research, it is proven that identifying error technique helps to increase students' understanding of learning mathematics. However, the study only observed the mathematical errors made by students in pre and postquizzes. Hence, future research is recommended to observe the performance of students in continuous assessment such as quizzes, tests and final examination by using identifying error technique.

\section{REFERENCES}

[1] Ajai, J.T. \& Imoko, I.I. (2015). Gender differences in mathematics achievement and retention scores: A case of problem-based learning method. International Journal on Research in Education and Science (IJRES), 1(1), 45- 50.

[2] Booth, J.L., Lange, K.E., Koedinger, K.R., \& Newton, K.J. (2013). Example problems that improve student learning in algebra: Differentiating between correct and incorrect examples. Learning and Instruction, 25, 24-34.

[3] Chamundeswari, S. (2014). Conceptual Errors Encountered in Mathematical Operations in Algebra among Students at the Secondary Level. Journal of Innovative Science, Engineering \& Technology 1(8).

[4] Effandi Zakaria \& Siti Mistima Maat (2010). Analysis of Students' Error in Learning of Quadratic Equations. International Education Studies, 3(3). 13. Shamsuddin, I.S. (2003). Dia

[5] Geary, D.C. (2004). Mathematical and learning disabilities. Journal of Learning Disabilities 37(1): 4-15

[6] Marzano, R. J., Pickering, D. J., Arredondo, D. E., Blackburn, G. J., Brandt, R. S., Moffett, C. A., Paynter, D. E., Pollock, J. E. \& Whisler, J. S. (1997). Dimension of Learning Trainer's Manual, 2nd Ed, Aurora, Colorado: McREL.

[7] Mohd Zulfabli \& Siti Salwa (2014). Tahap Penguasaan Matematik Dalam Kursus Kejuruteraan di Politeknik. Prosiding 021CiE-TVET 2014 (pp. 328 - 342).

[8] Nathan V., Lauren, Sarah. L, Adam \& Nathan, S. (2002). Difficulties with Maths: What Can Stand in the Way of a Students' Mathematical Development. Misunderstood Minds. Retrieved on 4th Sept 2009 from http://www.misun derstoodmind/math_skill

[9] Siti Nursyahirah Zainudin, Wan Hartini Wan Hassan, Siti Ramizah Jama, Siti Fairus Fuzi, Nurul Emyza Zahidi, Bushra Abd. Halim (2018), Mathematical Errors in Intensive Mathematical Errors in Intensive Mathematics I Course: A Case of Mengubah Destini Anak Bangsa (MDAB) Programme Students in Unversiti Terknologi Mara (UiTM) Melaka, Vol 1, Journal Herald National Academy of Managerial Staff of Culture and Arts, 600-605

[10] Stendall, R. (2009). Use Your Six Intellectual Factors to Achieve Anything in Your Life. Article-idea. Retrieved on 4th Sept 2009 from http://www.articleidea.com/profile/raystendall-.

[11] T, Tambychik \& T.S. Mohd Meerahb. (2010). Procedia Social and Behavioral Sciences 8: 142-151. Students' Difficulties in Mathematics Problem-Solving: What do they Say?

[12] Yee, M. H., Widad Othman, Jailani Md Yunos, Tee, T. K., Razali Hassan, \& Mimi Mohaffyza Mohamad (2011). The level of Marzano higher order thinking skills among technical education students. International Journal of Social Science and Humanity, 1(2). 